\title{
Negotiating Identity: Politics of Identification among the Borana, Gabra and Garri around the Oromo-Somali Boundary in Southern Ethiopia
}

\author{
Synopsis of a PhD Dissertation*
}

Fekadu Adugna $^{1}$

\section{Background}

Identity negotiation has a limited scope constrained by pre-existing memories of identification and political and economic circumstances. It is often motivated by the contexts in which the individuals and the collectivities find themselves in, especially under the condition of rapid socio-political change. Presumed common ancestry, history, language, religion and custom can be considered the raw materials of identity construction (Nagel 1994; Cornell 1996; Schlee 2007). They either inform or constrain the processes of identification of an individual or collectivity. However, since the publication of Barth's (1969) seminal book, Ethnic groups and boundaries, the focus of investigation of the scholars of ethnicity and identity has changed from the totality of the 'objective' features of a group or groups to a selection of the actors' most significant features in a given situation. In the same line of argument, in this thesis, I attempted to show how the ethnic actors negotiate and (re)construct their identity by selectively emphasizing and de-emphasizing the raw materials of identification in different contexts within the given options. Actors use the most relevant identity markers at a certain moment, which could be inversed in another situation. They strategically and inventively 'remember' or 'forget' the markers of identification. However, not all the groups and individuals have equal raw materials of identifications, nor can they all be used strategically and selectively in the construction of identity. Even though a lot of calculations, negotiations and selection of raw-materials of identification - and even (re)construction and invention - have been taken into account in the choice making processes, the construction of identity is not arbitrary. Identity constructions 'never occur in a vacuum' (Cornell and Hartmann 1998: 197).

The research on which the thesis is based was designed as a response to the

\footnotetext{
* Defended, December 2009, Max Plank Institute for Social Anthropology and MartinLuther University, Halle-Wittenberg, Germany

${ }^{1}$ Assistant Professor, Department of Social Anthropology, Addis Ababa University
} 
rapid political changes, violent conflicts and the recent institutionalization of ethnicity in Ethiopia, and the explosion of ethnicity discourse in general. The main question the dissertation set to answer was how individuals and collectivities decide their belonging or construct their identities within the available range of options of identifications, in varying circumstances. I use 'identification' as a process of claiming belonging to broader ethnic groups or ethno-national states and even national states. 'Belonging' here is less about emotion than about historical, cultural, and the perceived advantages one would get through belonging to one of the ethno-national groups or national states.

My data came from the Borana, Gabra and Garri. The Borana, Gabra and Garri are located at the triangular borders of the three states in Northeast Africa Ethiopia, Somalia and Kenya. In ethnic and linguistic terms, they are at the boundary of two major ethnic groups of the Horn of Africa: Somali and Oromo. All the three groups speak Afaan Oromo; and most of the Garri and an insignificant number of the Gabra also speak Somali. Potentially, but not equally, the Borana, Gabra and Garri could identify with any one of these nationalisms: state, ethnic or linguistic. Though I examined different historical circumstances, emphasis has been given to how the Borana, Gabra and Garri took sides and constructed identity in the context of conflicts such as Ethiopia-Somalia war of the 1960s and 1970s, and to the recent ethno-national identity politics where ethnicity is a formal organizing principle of the administrative structure in Ethiopia.

In both contexts, the national states (Somalia and Ethiopia, and to less extent Kenya) and the broader ethnic groups (Somali and Oromo) posed claims over the Borana, Gabra and Garri. The actors among the Borana, Gabra and Garri have also engaged in negotiations, claims and counter claims. These negotiations, claims, counter-claims and resistances were mostly framed in ethno-national terms. In such instances, these peripheral groups: the Borana, Gabra and Garri, were forced to take sides and construct belonging to one of the broader ethnonational groups or national states. I emphasize the process of identification at micro-levels in response to the actions at the macro-structure such as rapid changes in state policies, ethno-national movements and national and international politics, which have often been accompanied by conflicts. During such moments, the Borana, Gabra and Garri have had to (re)construct their identity within the given context either by accepting or resisting the categorization by the more powerful actors such as the state/s and ethno-nationalists. I found myself intrigued by the questions such as how do people identify themselves, and are categorized by others? How emerging nationalisms have impacted on the shaping and reshaping of identification processes at the local levels. What are the rationales for taking sides in a conflict situation? 


\section{The Past in the Present Narratives}

I started the presentation of my ethnographic work, in the second chapter, by examining the present narratives of the Borana, Gabra and Garri in the forms of myths of origin, fission, history of migration, (re)constitution and different kinds of historical inter-group relations. I reconstructed the identification process of the past to the extent that it is made relevant by actors in the identity politics of the present. How people understand the past matters, because it can help understand how they imagine the present and, of course, the future, and act on that basis. The past is selectively remembered, narrated, forgotten, or even invented as a political resource for the actors to justify a number of contested power and resource claims which are currently at stake (see also Chapman et al 1989: 5; Sorenson 1993: 3976; Schlee and Shongolo 1995: 15-16; Triulizi 2006). I have not examined the past for the sake of 'authentic' history per se; rather I discussed the past from the peoples' point of view and my interest was how the interpretation about the past factors in the current identification process. My informants remembered, constructed and narrated the past with reference to the current political landscape and their interests are how the 'recollected past' could impact their present identity politics. The narratives I am (re)presenting in the thesis were made in the context of institutionalized ethnic-politics and heightened inter-group animosity. This is a moment when people around Oromo-Somali boundaries are constantly preoccupied with defining and redefining their identity.

Thus, Instead of reconstructing their history by taking my own critical perspective, I rather highlighted how their emic understanding of their history informs or constrains their current struggle for identification. In other words, by placing the different historical narratives in the present concern of the actors, I examined how the historical and cultural raw materials can be instrumentalized in the present-day struggle to construct their historical relatedness with and difference from the broader ethnic groups: the Oromo and Somali and of course the relations among themselves.

To this effect, I have discussed different assumed descents and claimed places of origins as well as different migrations. The Borana oral historians trace their origin to a place northeast of their present territory. According to the Borana elders, this place of origin is where fissions of the Oromo took place. By substantiating this narrative of fission and migration with the sharing of common lineages and custom with other Oromo groups, the Borana elders indisputably narrate their identification with the broader Oromo ethnic group.

Quite differently, the Gabra and Garri claim to have migrated from Yemen. The Garri even trace their genealogy to Prophet Mohamed's family. The idea of their origin and the story of their migration connect the Gabra and Garri to the region known as the Holy land of the Muslim - to the Islamic Great Tradition. 
Whether this is authentic claim or not is a different investigation. In practice, however, claiming descent from a common assumed place of origin serves as a broad assertion of common ancestry, and denying having common place of origin is denying common ancestry. The broader Somali also make similar claim, including the genealogical relation to the family of the Prophet. For the Garri and Gabra, claiming relation to Arabia is today in a way claiming connection to the Somali, and the Garri could even trace their descent to the Somali 'national genealogy'. In this regard, in the present context in Southern Ethiopia and northern Kenya, the Borana on the one hand and the Gabra and the Garri on the other hand, are signifying different ancestry. The Garri and Gabra emphasize their common descent and difference from the Borana.

However, the Garri-Gabra claim of common descent had not been manifested until the emergence of the Somali nationalism that prompted the need to form alliance. They claim, interestingly, that until that time the knowledge of common descent had remained part of their memory through the names of clans they share and through their similar camel marks. On the other hand, the Gabra have a longstanding inter-clan custom and ritual affiliation with the Borana. They had been affiliated to the Borana, and even integrated into the Borana's custom and resource use. They had been considered as 'low caste Boranas' (Donaldson-Smith 1896 cited by Belete 1999: 20), and 'vassals of Borana' (Haberland 1963: 141148). There had been also occasions when the Gabra had taken on the Borana identity. As a result of this dynamic ethno-genesis - including a claimed inter-clan descent relationship with the Garri and inter-clan custom and ritual affiliation with the Borana - the Gabra are at the core of identity contestation and negotiation in the current politics of identification around the Oromo-Somali boundary. This situation gave the contemporary Gabra actors a greater degree of selectivity, but under enormous politico-economic constraints.

Pastoral Access to Key Resources and Associated Identity

In the third chapter, by pausing from pursuing the strand of discussion I have started in the previous chapter, I emphasized on the interaction between the pastoral groups and individuals around pastoral resources, especially water wells. To fully understand the processes of identification, I argue, we need to examine the distribution of pastoral resources, and how the resource regimes appear in different cultural frames. Looking at a resource shows how the politics of identity relates to the day-to-day life of pastoral communities. In the later chapters I will emphasize the role of the elite in identification processes. In that regard this chapter addresses a crucial question: if the elite act within the framework of the states' or ethno-nationalists' politics of identification, how does identity politics give sense to the "non-elite" pastoralists? It is this question that necessitates a 
brief discussion of the pastoral resources.

My argument in this chapter is that access to the critical resources, especially the scarce water wells, played a significant role in shaping the pastoral livelihood and interaction of the Borana, Gabra and Garri as well as in their identification with the broader entities. These resources are so crucial that local discourses have been articulated about, and wars have been fought over these wells. Formation of local alliances, shifting allegiances and individual switching of identity were shaped partly, if not only, by putting these key pastoral resources, especially the water wells, at the center of their imagination and decision making processes. Different regimes that have ruled Ethiopia have manipulated access to the same resources again and again in their relations with the local groups. They allocated wells to the groups they favored, by snatching it from the groups they considered as adversaries or at least as allies of their adversaries.

\section{The Emergence of Nationalisms and Politics of Identification}

Chapter four presents the intertwining of the international and the national politics as well as the local politics of identification. In the 1960s the young independent Republic of Somalia set out to unite all Somali in northeast Africa in one state. With this mission, it went on to claim territories in which people of Somali ethnic origin live from its neighbours, mainly, Ethiopia and Kenya. The Somali nationalists' claims and the response from Ethiopia and Kenya resulted in protracted secessionist guerrilla warfare in southern and eastern Ethiopia as well as in northern Kenya. To win the support of the politically marginalized pastoralist groups, among others, the Borana, Garri and Gabra, the Somali nationalists evoked relatedness in terms of cultural markers and kinship relation and categorized all the three groups as Somali. This prompted the issue of who belongs to the Somali and who is not; who takes side with the Somali cause and who does not, and what is the criteria of taking side. The Garri readily accepted the categorization with the Somali on the grounds of the pre-existing raw materials of identifications such as assumed common descent and cultural markers, which they selectively used, and joined the Somali insurgents. Of course, the attraction by the new promises from the Somali ethno-nationalism vis-à-vis their fragile integration into the Ethiopian and Kenyan states should not be undermined.

On the other hand, this same argument was unconvincing for the Borana, especially the non-Muslim Borana, who could not be persuaded to become Somali or to be affiliated to the Somali without any supporting raw materials - cultural markers, the ideology of descent and history of amicable relation. Rather, it evoked a longstanding history of competition and conflict over resources. In other words, the Borana's categorization, i.e., external assignation as Somali by the 
Somali was not supported by the internal definition that takes into consideration their pre-existing raw-materials of identifications, and thus it was unsuccessful. The Gabra who had the same position with the Borana at the beginning of the conflict, gradually changed their affiliation from the Borana to the Garri. They selectively and intentionally re-examined their oral histories and 'remembered' their 'cross-cutting inter-clan relation', as Schlee calls it, with the Garri (Schlee, 1989). The Gabra joined the Somali insurgent movement, following the Garri, by denouncing their longstanding ties with the Borana and even by negatively interpreting those histories.

The fact that the Borana refused and the Gabra were convinced to embrace Somali identity, and changed their affiliation was not only a matter of their elites' entrepreneurial ability. The Borana's refusal shows the limit of outright invention of belonging and solidarity. The Gabra have used the existing raw materials of identification strategically and selectively based on the situation at hand. They reoriented themselves and redefined their identity and affiliated to the Somali, by selectively evoking their identity markers (Barth 1969).

The Republic of Somalia created an enabling situation for these peripheral groups by establishing a rebel organization - the Somali Abo Liberation Front an organization that spoke the Oromo language and fought for the interest of the Republic of Somalia. With the Somali claim and the Ethiopian counter-claim clashing, eventually, Oromo nationalism emerged from within Ethiopia with yet another map that contradicted both the Ethiopian and the Somali claims.

\section{Ethnic Federalism and Politics of Identification}

The dynamism of ethnicity in Ethiopia in general and the politics of identification among the Borana, Garri and Gabra in particular reached climax in the post 1991 phenomena, which is discussed in chapter five. The ethnic based federal system, and the role ethnicity plays as an organizing principle of the state as well as the ensuing political dynamism have several effects on the politics of identification. The most important one is that ethnicity is intertwined with resources and consequently ethnic identity politics have become more important than ever before. Resources such as state allocated budget, job opportunities, and service providing sectors including schools, health centers, and relief food distributions are channeled along the newly established ethno-national states. This has fundamentally impacted on the politics of identification among the Borana, Garri and Gabra that are situated on the boundary of Oromia and Somali national Regional States. Belonging to either the Oromo or Somali has become crucial for them, and in fact, it resulted in the creation of very talented ethnic entrepreneurs, especially among the Garri and Gabra. In these circumstances, they revisited and strategically (re)negotiated and (re)defined their identification with the Oromo or 
Somali. But their negotiations have always been informed and constrained by the pre-existing history of relatedness and differences which they selectively emphasized and deemphasized in response to the new political and economic incentives. For the Borana who have better pastoral resource under their control and have indisputable connection to the broader Oromo, the current process of identification is shaped by the new political dynamism, which activated the historical memories including common assumed descent and customs with the broader Oromo, and the image of the strong enemy other: the Somali.

As Mentioned above, the Garri were not only aware of their Somali identity but also fought against Ethiopia and Kenya under the banner of Somali nationalism in the 1960s and 1970s. However, this has not hindered them from revisiting and renegotiating on their identity. In 1991, regardless of the memory of past identification and cultural markers, the Garri political and business elite paid attention to the immediate advantage of identification with the Oromo who are the majority in the country. They renamed their political party - the Somali Abo Liberation Front - in which they were better represented to become Oromo Abo Liberation Front. This action was part of their negotiation to be identified with the Oromo, a temporary switch from Somali identity that was by then facing severe political crisis. Though briefly, they succeeded in identifying themselves with the Oromo, including incorporation into the Oromia National Regional state and managed to control key local offices. That time the Garri emphasized common language and longstanding neighborliness and deemphasized the ideology of descent. However, after four years of 'becoming Oromo', and as they felt some frustration in their progress, and with a new political and economic opportunity rising on the Somali side, the Garri switched back and joined the Somali again by reversing the significance of the most relevant identity markers. Their multilingualism favored them to comfortably switch between the two categories.

Even a more interesting case is that of the Gabra that have a deep ethnohistorical substratum and 'thick' cultural features that would relate them to both the Oromo and Somali. As belonging to either Oromo or Somali is a factor that opens up opportunities in the livelihood of the people, the Gabra officials, businessmen, students and elders paid attention to the immediate advantage of identification with one of these broader ethnic groups. They identified themselves with the one where they perceived real or imagined advantages. Most of them identified themselves with the one that offered them jobs or business opportunities. Those who secured some opportunity in the Somali National Regional State claimed Somali-ness and those who got some opportunity in Oromia National Regional State claimed Oromo-ness. They were effectively divided between the two ethnicities, i.e. Oromo and Somali. Both sides co-opted elders who would help them in legitimizing their identity claims. Both sides are 
busy in reconstructing politically motivated traditions and publicly performing them in a way they fit into their present situations. When individuals switch from one category to the other, which is a common practice, they just alter the significance of the most relevant markers.

\section{Politics of Identification, Contested Borders and Territoriality}

In my last ethnographic chapter, I have discussed how the state policies that equate ethnic group with administrative unit have intensified claims and counterclaims and contestation over territory between the Oromo and Somali around their ethno-national regional borders, and its relation to the processes of identification of the Borana, Garri and Gabra. The claims include water points, tracts of land and pasture, ritual sites and towns. Some towns, including Moyale, even came under double and competing administrative structures. This contestation and conflict has been mirrored and explained at the local level through the conflicts between the Borana and the Garri who reformulated and reframed their longstanding competition over pastoral resources in line with the new ethnonational administrative structures. The federal government's activity to undertake referendum to determine the fate of the contested territories by majority vote further intertwined ethnic belonging with resources. The inhabitants were forced to vote for their belonging to one of these ethno-national regional states. Economically, the vote put the inhabitants either in a total control or in total lose of the resources. This had increased the role of ethnic belonging to the survival of the livelihood of these pastoralists and heightened the politics of identification.

In the situation of an intensified competition and contestation between the Garri and the Borana at the local level and between the Somali and the Oromo in the national political arena, the Gabra were pressed to decide on their identity and show allegiance to either the Oromo or Somali. For the Gabra standing 'betwixt and between' has become difficult because they could not afford to lose the pastoral ground and the opportunities they would get from the state. As a result the division within the Gabra along the competing Oromo and Somali identity has been intensified.

\section{Conclusion}

The processes of identification among the Borana, Garri and Gabra, addressed in this dissertation, have shown to be complex, contingent, historical and politicoeconomic. Identity negotiation has a limited scope constrained by pre-existing memories of identification, history of inter-group relation, the differential access to resources as well as the emerging political and economic circumstances. It is often motivated by the contexts in which the individuals and the collectivities find themselves in, under the condition of rapid socio-political change. 
The processes of identification of the Gabra and Garri have been shaped by several structures that condition the identity choice. These groups constructed their identity at the margin of several ethnic groups and states. Their earlier ethnogenesis was constructed at the margin of the Borana Oromo traditional believers and the Muslim Somali. Today, they have overlapping features taken from both cultures. Since the beginning of the twentieth century they have been at the margin of three states: Ethiopia, Somalia and Kenya. Presently, they find themselves at the margin of new actors in the political economy in Ethiopia: the Oromo and the Somali ethno-nationalists and their respective ethno-national regional states. Their ethnic identity has been constructed in a way that they could use a range of opportunity structures from all these ethnic groups, ethno-national regions and states. But at the same time they have been constrained by all these powerful actors.

\section{References}

Barth, Fredrik. 1969a. Ethnic Groups and Boundaries. Boston. Little, Brown

Belete Bizuneh. 1999. "Inter-Ethnic Relation in Borana (Southern Ethiopia) A Historical survey to 1943. M.A Thesis Addis Ababa University

Cornell, Stephen. 1996. The available ties that bind: content and circumstances in ethnic processes. In Ethnic and Racial Studies 19(2): 265-289

Cornell, Stephen and Hartmann, Douglas. 1998. Ethnicity and race, making identities in a changing world. London: Pine Forge Press

Chapman, Malcolm, et al. 1989. 'Introduction,' In Elizabeth Tonkin et al (eds.) History and ethnicity. London: Routledge

Haberland, Eike.1963. Galla Süd-Äthiopiens. Stutgart: W. Kohlhammer Verlag.

Nagel, Joane. 1994. Constructing Ethnicity: Creating and Recreating Ethnic Identity and Culture. Social Problems, 41 (1): 152-176

Schlee, Günther. 2007. The Brothers of the Boran once again: on the fading popularity of certain Somali identities in Northern Kenya. Journal of Eastern African Studies. 1 (3):417-435. . 1989. Identities on the Move, Clanship and Pastoralists in Northern Kenya. Gideon S. Were Press, Nairobi.

Schlee, Günther and Abdullahi A. Shongolo. 1995. Local war and its impact on ethnic and religious identification in southern Ethiopia. Geo Journal 36 (1): 7- 17

Triulzi, Alessandro. 2006. The past as contested terrain, commemorating new sites of memory in war-torn Ethiopia. In Preben Kaarsholm (ed) Violence, political culture and development in Africa. Oxford: James Curry 